\title{
Ciência(s) e Pesquisa no Contexto Escolar: Concepções e Limitações
}

\section{Science(s) and Research in the School Context: Conceptions and Limitations}

Diógenes Gewehr ${ }^{1}$; Andreia Aparecida Guimarães Strohschoen ${ }^{1}$

\section{RESUMO}

Este artigo problematiza a visão de ciência e pesquisa de alunos e professores da Educação Básica. Buscou-se compreender como tem sido realizada a pesquisa no contexto escolar, partindo do pressuposto de que, para alunos e professores, este processo parece não estar claro, limitando as possibilidades pedagógicas de ensino e aprendizagem. Também, a definição do que é ciência pode estar sendo concebida de maneira equivocada e restrita, produzindo uma distorção da realidade. Nesta pesquisa, empírica e qualitativa, aplicou-se um questionário semiestruturado com 18 professores e 31 alunos dos Anos Finais do Ensino Fundamental. Os dados foram categorizados e interpretados mediante Análise de Conteúdo. Observou-se que muitos alunos e professores não têm compreensão clara do que seja ciência, confundindo-a com a disciplina Ciências. Quanto a prática da pesquisa, constatou-se que ocorre de modo incipiente: alunos relatam que é realizada principalmente por meio de exercícios em aula; professores, em sua maioria, não se consideram pesquisadores. Percebeu-se um modo de pesquisar baseado em cópias de conteúdos, com poucos (ou nenhum) elementos que favoreçam a emancipação dos alunos.

Palavras-chave: Senso comum. Conhecimento científico. Ensino. Aprendizagem. Educação Básica.

\begin{abstract}
This article problematizes the vision of science and research of students and teachers of Basic Education. It was sought to understand how research has been carried out in the school context, assuming that, for students and teachers, this process seems not to be clear, limiting the pedagogical possibilities of teaching and learning. Also, the definition of what science is can be misconceived and restricted, producing a distortion of reality. In this empirical and qualitative research, a semi-structured questionnaire was applied with 18 teachers and 31 students from the Final Years of Primary Education. The data were categorized and interpreted through Content Analysis. It has been observed that many students and teachers have no clear understanding of what science is, confusing it with the Science discipline. Regarding the practice of the research, it was verified that it occurs in an incipient way: students report that it is performed mainly through exercises in class; teachers, for the most part, do not consider themselves researchers. It was perceived a way of searching based on copies of contents, with few (or none) elements that favor the emancipation of the students.
\end{abstract}

Keywords: Common sense. Scientific knowledge. Teaching. Learning. Basic education.

${ }^{1}$ UNIVATES - Universidade do Vale do Taquari, Lajeado/RS - Brasil. 


\section{INTRODUÇÃO}

"Quem nasceu primeiro, o ovo ou a galinha?" Esta é uma pergunta trivial que possivelmente grande parte das pessoas já ouviu ou ouvirá em sua vida. Em uma fração de segundos, atualmente, é possível encontrar diversas teorias e suposições que atestem para a resposta. Basta digitar a frase no Google que, em 0,73 segundos, são trazidos aproximadamente 1.150 .000 resultados ${ }^{2}$. Na busca realizada, 0 primeiro site que traz a resposta é o portal de notícias UOL, onde consta:

Apesar de o senso comum dizer que o ovo veio antes da galinha, há cientistas que afirmam que foi a galinha que surgiu antes de botar o ovo. Pela teoria da evolução, era necessário um ovo com um zigoto de galinha dentro, para a galinha nascer. Assim, o ovo com o pintinho dentro teria surgido primeiro. Já outra linha de pesquisa acredita que o ovo da galinha é diferente dos outros ovos e só seria feito a partir de substâncias presentes na galinha adulta, portanto, a galinha teria aparecido antes (UOL, 2013, texto digital).

Observa-se, no fragmento, que não há uma definição para a questão, assim como não há precisão da resposta nos demais resultados da busca. Entretanto, o que se pode ter com clareza são duas visões distintas a respeito de um mesmo fenômeno: o senso comum e o conhecimento científico, ainda que neste último também não haja um consenso para a resposta.

Longe de querer se aprofundar na questão específica (quem nasceu primeiro?), este artigo problematiza a visão de ciência e pesquisa de professores e alunos dos Anos Finais do Ensino Fundamental, de quatro escolas municipais de duas cidades do Vale do Taquari/RS/BRA. Alunos e professores foram questionados sobre suas concepções de ciência; como a percebem no cotidiano; o que entendem por pesquisa; se julgam-se pesquisadores; como a pesquisa é desenvolvida; se confiam plenamente em pesquisas científicas. Tais questões foram abordadas a partir das concepções do senso comum dos entrevistados, não adentrando com os mesmos os conceitos do senso científico sobre as temáticas.

Teve-se como objetivos compreender como tem ocorrido o processo de pesquisa no contexto escolar, partindo do pressuposto de que para alunos e professores este processo parece não estar claro, limitando as possibilidades pedagógicas de ensino e de aprendizagem por meio da pesquisa. Também, a definição do que é ciência pode estar sendo concebida de maneira equivocada e restrita, produzindo uma distorção da realidade. Estas são percepções dos pesquisadores autores deste manuscrito, desencadeadas a partir de vivências no contexto escolar.

\subsection{Ciência, senso comum e conhecimento científico}

Existe uma crença difundida na sociedade de que o conhecimento gerado pela ciência é indubitável. As propagandas vinculadas na mídia que mostram profissionais demonstrando e validando produtos, geralmente fazendo uso de trajes brancos que remetem a imagem de cientistas, ganham "aprovação geral", por serem considerados cientificamente comprovados. Configura-se o conhecimento científico "[...] por um grau de certeza alto, desfrutando assim de uma posição privilegiada com relação aos demais tipos de conhecimento [...]. A autoridade da ciência é evocada amplamente" (CHIBENI, 2017,

\footnotetext{
${ }^{2}$ Consulta realizada em 21/04/2017, por meio de provedor de Internet a rádio com velocidade de 8 MB. Dados gerados automaticamente pelo site de busca Google.
} 
p. 1). Desta forma, os produtos se autoqualificam e tendem a vender mais, já que têm o aval da ciência.

Mas afinal, o que é ciência? Como um conhecimento deixa de ser popular e torna-se científico? Segundo Demo (2000, p. 13) toda definição é, de certa forma, indefinida e insuficiente, "é apenas aproximativa, porque nenhum fenômeno tem contornos nítidos, muito menos fenômenos sociais e históricos. Definir é colocar limites". Ao procurar definir tenta-se deixar mais claro, contudo, corre-se o risco de "empobrecer o fenômeno", pela redução aos limites. Assim, toda e qualquer definição supõe a visão daquele que o define naquele momento, pois uma definição nunca é completa, podendo ser sempre revisada.

Definir o que é ciência é complexo, pois envolve múltiplas áreas, fatores, espaços, entre outros. Tornase mais fácil procurar entender onde a ciência se insere do que propriamente defini-la. A ciência, ao englobar diversos contextos, se tornou um conhecimento fascinante, "supera todas as outras formas de conhecimento, sobretudo porque chega mais perto da verdade e pode ser usado para transformar a realidade de tal maneira que foi capaz de moldar o mundo moderno" (MBARGA; FLEURY, 2017, p. 97), remodelando áreas como a saúde, alimentação, comunicação, habitação, segurança, entre outras, influenciando a vida de todos.

A ciência é dinâmica e mutável, faz parte do dia a dia e está frequentemente se reinventando. Decorre de uma construção humana pautada em descobrir, esclarecer, duvidar, mudar, não sendo algo acabado e sim em constante evolução, redescobrindo-se repetidamente (BORGES, 2010). Origina-se no conhecimento popular, no senso comum, para então aperfeiçoar-se e tornar-se científica:

Em termos genéricos, o senso comum é a bagagem cultural e evolucionária que trazemos conosco, por meio da qual sabemos constituir família, educar os filhos, alimentar-nos, cuidar da saúde, sem necessariamente sermos pedagogos ou médicos; [...]; essa bagagem, em condições normais, não é colocada em questão e, por isso, faz parte da aceitação comum. O conhecimento científico representa a outra direção, por vezes vista como oposta, de derrubar o que temos por válido; mesmo assim, em todo conhecimento científico há sempre componentes do senso comum, à medida que nele não conseguimos definir e controlar tudo cientificamente (DEMO, 2000, p. 23).

Com estas "definições", podemos observar que o senso comum é tão digno quanto o senso científico, não é desprezível, devendo ser respeitado. É a partir do senso comum que surgem as ideias para então serem estudadas e validadas. Para Fontana (2006, p. 1) "a ciência é uma metamorfose do senso comum. Sem o senso comum, a ciência não pode existir". Assim, o desenvolvimento da ciência decorre do progressivo desenvolvimento do senso comum.

Mendes (2013, p. 15) exemplifica a diferença entre senso comum e científico a partir de "opinião" e "ciência".

Seria correto pensar que a verdade científica é uma questão de opinião e que varia de pessoa para pessoa? É possível afirmar que a lei da gravidade existe para alguns e para outros não? Ou que a existência do genoma é uma questão de ponto de vista? Obviamente, não. Geralmente, aceita-se o conhecimento produzido pela Ciência, até que apareça uma prova em contrário. 
A opinião é algo pessoal, particular, cada um tem a sua opinião. Como muda de pessoa para pessoa ela não tem muita legitimidade. Já a ciência produz um conhecimento mais sólido, podendo ser justificada por experimentos e demonstrações, legitimando-a (MENDES, 2013).

Fontana (2006, p. 7) complementa: "Como a ciência não pode ser definida em função de seu conteúdo, pois ele tem sofrido profundas revoluções ao longo da história, é definida por seu método". Mbarga e Fleury (2017) indicam que a ciência ao estabelecer rigorosas metodologias procura, com instrumentos confiáveis, reunir evidências para provar ou refutar determinada hipótese, avaliando e reexaminando seus próprios métodos e provas.

Mesmo que a ciência busque a verdade, os resultados científicos não são verdades definitivas nem nada parecido com mandamentos divinos; os cientistas estão sempre questionando e nunca ficam satisfeitos com sua própria verdade. Além disso, a publicação de resultados é sempre um convite para que outros pesquisadores verifiquem sua precisão (MBARGA; FLEURY, 2017, p. 97, grifo do autor).

Neste sentido, Demo (2000, p. 26) em encontro as ideias de Mbarga e Fleury (2017), refere-se ao conhecimento científico como algo que "não produz certezas, mas fragilidades mais controladas", não podendo a ciência oferecer conceitos "perenes, universalmente válidos", de modo a responder as perguntas com absoluta certeza, estando exposta a erros. Para corroborar tais perguntas, a pesquisa é um instrumento fundamental no processo científico, de modo a rever e aperfeiçoar respostas, esclarecendo-as ou fazendo surgir novas perguntas.

Demo (2009) problematiza em sua obra 'Pesquisa: princípio científico e educativo" que o processo da pesquisa não deve ser somente para "iluminados", àqueles que têm trajetória acadêmica, mas que a pesquisa deve ser "desmistificada", tomando como base a realidade (da qual decorre o conhecimento popular), sendo utilizada como instrumento do processo educativo desde a Educação Básica, como veremos a seguir.

\subsection{A pesquisa como instrumento pedagógico emancipatório}

A pesquisa é um processo pedagógico que aparece em todas as etapas escolares. A visão de pesquisa como algo simples ou complexo depende do ponto de vista, da "definição" de cada um. No ambiente escolar não é incomum encontrar professores que ainda solicitam aos alunos que apenas abram o livro e copiem determinado assunto, reproduzindo em seus cadernos conteúdos pelo simples ato de copiar, sem muito aprofundamento ou discussão. "É comum o professor que apenas ensina [...], amealha certo lote de conhecimentos e, a seguir, transmite aos alunos, dentro da didática reprodutiva e cada dia mais desatualizada" (DEMO, 2009, p. 12).

Com a inserção das tecnologias digitais de informação e comunicação (TDICs) na vida moderna, em especial a Internet, o processo não é muito diferente. Os alunos digitam o assunto no Google e saem a copiar as primeiras páginas que aparecem (GEWEHR, 2016). Quanto muito selecionam trechos entre os sites, fazendo cópias de fragmentos no caderno ou utilizando as ferramentas de "copiar" e "colar" do computador, o que pode ser tornar um vício tentador (MENDES, 2013). Em ambas situações, analógica ou digital, este ato é chamado por professores e alunos de pesquisa.

A pesquisa é mais do que isto, copiar não deve ser sinônimo de pesquisar. A pesquisa deve ser encarada como um processo "emancipatório", de modo a oportunizar ao aluno a construção de seu 
conhecimento, através de análise e elaboração própria, reestruturando as informações encontradas (DEMO, 2009; MENDES, 2013).

Por outra, criar não é retirar do nada. [...] Precisamos reconhecer, no realismo do diaa-dia que marca e limita pessoas e sociedades, que criar já é o processo da digestão própria, pelo menos a impressão de colorido pessoal em algo retirado de outrem. Mesmo porque, de modo geral, assim começa a criação: pela cópia retocada (DEMO, 2009 , p. 17-18, grifo do autor).

Este processo argumentativo e reconstrutivo, o qual Demo (2011, p. 1, grifos do autor) chama de "questionamento reconstrutivo", torna-se um desafio para alunos e professores no entendimento de como a pesquisa se processa e sua importância para a educação. O desafio está em "construir a capacidade de (re)construir", desenvolvendo habilidades que favoreçam o "processo de formação da competência humana", transformando-a em um ato cotidiano, "até o ponto de tornar a pesquisa a maneira escolar e acadêmica de educar". Para Estrázulas (2013), professores e alunos têm se envolvido cada vez mais com a pesquisa, encontrando alternativas para modificar o cenário de ambientes escolares em que se mantém o ensino expositivo e a aprendizagem receptiva.

Demo (2011), ao retratar o desafio do "educar pela pesquisa", aborda um ensino direcionado para a formação de um sujeito competente, com consciência crítica e autonomia intelectual, capaz de realizar formulações próprias a partir das pesquisas realizadas. Perujo (2011, p. 11) menciona que em uma pesquisa esta é nossa contribuição no fazer ciência: "Temos a obrigação de acrescentar algo mais. E esse é o desafio: diferenciar-nos do ponto de partida", contribuindo para o avanço e a ampliação do conhecimento inicial.

Para Veiga (2010, p. 58), ensinar a pesquisar significa mexer com o espírito investigativo do aluno, despertando-Ihe a curiosidade. A pesquisa "é uma atividade inerente ao ser humano, um modo de apreender o mundo. Ensinar a pesquisar é tomar a pesquisa como instrumento de ensino, de aprendizagem e de avaliação. É o ponto de partida e de chegada da apreensão da realidade". Por conseguinte, aprender a pesquisar é fundamental para uma educação emancipatória.

\section{PROCEDIMENTOS METODOLÓGICOS}

Esta pesquisa, de caráter teórico, empírico e qualitativo, teve seus contornos iniciais em novembro de 2014, quando iniciaram-se as discussões sobre iniciação científica na Educação Básica, decorrentes do projeto PICMEL - um programa de incentivo à pesquisa fomentado pela CAPES/FAPERGS - em um centro universitário no interior do Estado do Rio Grande do Sul.

Na ocasião, foi aplicado um questionário semiestruturado impresso com 18 professores e 31 alunos dos Anos Finais do Ensino Fundamental, em quatro escolas municipais de duas cidades do Vale do Taquari/RS. Alunos e professores foram questionados sobre metodologias ativas de ensino e de aprendizagem (estudo já publicado) e concepções de ciência e pesquisa, discutido neste artigo.

Fizeram parte deste estudo professores de todas as áreas do conhecimento dos Anos Finais do Ensino Fundamental, as quais se dividem em: Linguagens, Matemática, Ciências da Natureza e Ciências Humanas, conforme o art. 13 da Resolução 7/2010, do Ministério da Educação (MEC) (BRASIL, 2010). Estes professores responderam o questionário por livre adesão, sendo provenientes de três escolas no município de Lajeado/RS e uma escola de Arroio do Meio/RS. Os alunos, estudantes de duas 
turmas da escola municipal de Arroio do Meio, cursavam o sétimo e o oitavo ano, tendo sido o questionário respondido em aula por todos. Professores e pais de alunos assinaram um termo de consentimento livre e esclarecido (TCLE) autorizando sua participação na pesquisa.

O questionário indagava professores e alunos quanto às seguintes questões: 1) Para você o que é ciência? 2) Em quais situações você percebe que a ciência faz parte de sua vida? 3) O que você entende por pesquisa? (alunos); Você se considera um pesquisador? (professores). 4) De que forma você desenvolve pesquisa nas tuas disciplinas com os alunos? (professores); Seus professores estimulam a realização de pesquisa em sala de aula? De que forma? Em quais disciplinas estas pesquisas são realizadas? (alunos). 5) Você vê as pesquisas científicas como atividades passíveis a erros ou que se pode confiar totalmente? O questionário foi aplicado com os participantes sem informações prévias sobre os assuntos abordados, visando conhecer as concepções dos alunos e professores sem qualquer interferência dos pesquisadores.

Os dados foram tabulados e analisados mediante Análise de Conteúdo (BARDIN, 2006), o qual apresenta três fases essenciais para o processamento das informações: $1^{a}$ ) pré-análise; $2^{a}$ ) exploração do material; $3^{a}$ ) tratamento de resultados, inferência e interpretação. Na primeira fase organiza-se os materiais e sistematiza-se as ideias iniciais, lendo, formulando hipóteses e objetivos e realizando marcações ou recortes nos documentos. A segunda fase é a exploração do material, definindo categorias e unidades de significação por aproximações de respostas. A terceira fase é o tratamento aprofundado dos resultados, na qual se interpretam os dados e realizam-se as inferências, dando os devidos destaques aos resultados por meio de uma análise crítica e reflexiva do conteúdo, enriquecendo a leitura dos dados coletados. Para a identificação dos participantes foram utilizadas as letras $A$ (aluno), e $P$ (professor), seguido de um numeral ( $1, A 2 \ldots P 1, P 2 \ldots)$. A seguir, serão analisadas e discutidas as categorias que emergiram das respostas dos alunos e professores, exemplificando-as com recortes de alguns trechos que representam a predominância das respostas nas categorias.

\section{ANÁLISE E DISCUSSÃO}

Por meio da análise de conteúdo (BARDIN, 2006), foi possível compreender as concepções de alunos e professores no que tange a ciência e pesquisa. Quando possível os resultados são apresentados e discutidos paralelamente, na visão dos alunos e dos professores, a respeito de um mesmo assunto.

Inicialmente, discute-se a concepção de ciência. Foi possível estabelecer três categorias que emergiram dos questionários dos alunos e professores: ciência como estudo/disciplina de sala de aula; ciência como pesquisa, descoberta, experiência; ciência como dia-a-dia e relação com o mundo.

A categoria mais citada, nos dois grupos, foi "ciência como estudo/disciplina de sala de aula", respondida por $17(54,8 \%)$ alunos ${ }^{3}$ e nove (50\%) professores ${ }^{4}$. Observa-se que, tanto alunos quanto professores, relacionaram a ciência com a disciplina escolar Ciências.

\footnotetext{
${ }^{3} \mathrm{~A} 1 ; \mathrm{A} 3 ; \mathrm{A} 4 ; \mathrm{A} 7 ; \mathrm{A} 12 ; \mathrm{A} 13 ; \mathrm{A} 19 ; \mathrm{A} 20 ; \mathrm{A} 21 ; \mathrm{A} 22 ; \mathrm{A} 24 ; \mathrm{A} 25 ; \mathrm{A} 26 ; \mathrm{A} 28 ; \mathrm{A} 29 ; \mathrm{A} 30 ; \mathrm{A} 31$.

4 P1; P3; P5; P8; P9; P10; P12; P13; P16.
} 


\section{Alunos}

"Ciências é parte de um conjunto de estudos" (A13).

"Uma matéria boa para o ensino da aprendizagem, que ensina coisas que nós nem pensávamos que podia existir" (A28).

"Estudo de plantas, animais, corpo humano" (A30).

\section{Professores}

"Estudo da vida" (P1).

"Área do conhecimento que estuda os seres vivos e o meio ambiente" (P3).

"Ciência é o estudo da vida, do ambiente em que vivemos e suas constantes transformações" (P8).

É possível perceber nas respostas dos participantes uma visão limitada do que é ciência e sua complexidade. Isto mostra que os alunos, sujeitos em formação inicial, estão tendo uma visão distorcida e restrita da ciência, possivelmente por seus professores passarem esta visão em sala de aula. Se assim a entendem, não dimensionam para os alunos que ciência vai muito além da disciplina escolar englobando, conforme expresso por Mbarga e Fleury (2017), áreas como a saúde, comunicação, habitação, alimentação, segurança, entre outras, influenciando e remodelando o mundo moderno.

A segunda categoria, "ciência como pesquisa, descoberta, experiência", faz compreender que, para $10(32,2 \%)$ alunos ${ }^{5}$, aproximadamente um terço, a ciência está relacionada a experiências e invenções, decorrentes de uma pesquisa. Já para seis $(33,3 \%)$ professores $^{6}$, igualmente um terço, ela é vista como uma pesquisa científica passível de comprovação.

\section{Alunos}

"Ciência é para mim quando eles criam novos remédios" (A8).

"É fazer experiências" (A14).

"Ciências é o estudo de plantas e animais. É dentro de um laboratório que se faz testes" (A23).

\section{Professores}

"Ciência é tudo aquilo que pode ser comprovado, em termos de conhecimento. Ciência é prática" (P2).

"Ciência é todo conhecimento adquirido através do estudo, da pesquisa" (P4).

"É o conjunto de conhecimentos, referentes a determinado assunto, comprovados via pesquisa" (P6).

Esta categoria vê a ciência como descrita por Borges (2010), dinâmica e mutável, pautada na dúvida, investigação e descobrimento. Entretanto, a ciência é posta como algo necessariamente

\footnotetext{
${ }^{5}$ A2; A8; A9; A10; A14; A15; A16; A17; A18; A23.
}

${ }^{6}$ P2; P4; P6; P7; P11; P18. 
experimentável, no sentido prático, comprovada mediante pesquisa. Também, como uma atividade que resulta em invenções.

Na descrição de A23 "dentro de um laboratório..." é possível observar o que Borges (2010, p. 6) fala sobre a visão que muitas pessoas têm de que a ciência é baseada apenas em experimentações que ocorrem dentro de um laboratório, geralmente relacionando-a a atividade de cientistas, "[...] como se pela experimentação fosse possível deduzir a teoria e que o cientista possui apenas os experimentos como fontes de pesquisa e de dados", mostrando uma visão reducionista da atividade científica.

A última categoria sobre a visão de ciência, "ciência como dia-a-dia e relação com o mundo", decorreu das respostas de três (9,8\%) alunos (A5; A6; A27.) e três (16,7\%) professores (P14; P5; P17.), relacionando ciência com o cotidiano das pessoas:

\section{Alunos}

"Ciências eu acho que é quase tudo que acontece no nosso dia a dia" (A5).

"Para mim ciências é várias coisas diferentes [...] e também a conscientização de que o futuro pertence a todos" (A27).

\section{Professores}

"Ato de refletir e de se relacionar com o mundo, [...]" (P14).

"É a vida, o ser humano" (P15).

Nesta categoria observa-se uma amplitude maior do conceito de ciência, indo além de conceitos de sala de aula ou experimentações. Segundo Borges (2010) e Goldschmidt et al. (2014), a ciência não pode ser vista de modo simplista, está articulada a diversos fenômenos que ocorrem a nossa volta, e assim influencia nosso cotidiano. Dentre os participantes, somente um $(3,2 \%)$ aluno (A11) não opinou sobre o que entende por ciência.

A questão seguinte indagou os participantes em quais situações percebem que a ciência faz parte de sua vida. Desta questão emergiram quatro categorias, sendo duas comuns para alunos e professores: em todo momento; quando penso na origem, evolução e explicação das coisas; quando estou em contato com a natureza; em momentos específicos. Dois $(6,4 \%)$ alunos (A6; A11) não responderam esta questão.

A categoria "em todo momento" foi a resposta de apenas três (9,8\%) alunos (A5; A13; A27), enquanto que no grupo de professores aqueles que relacionam ciência a todas atividades do cotidiano, em um contexto amplo, somaram $12(66,7 \%)$ professores ${ }^{7}$, ou seja, dois terços dos participantes.

\section{Alunos}

"Eu acho que ciências é parte da minha vida em todo o momento" (A13).

"Em praticamente todas, pois com ela estudamos as plantas, os animais e todos os seres vivos, por isso em cada canto que olhamos, lembramos da ciências" (A27).

\footnotetext{
7 P1; P2; P3; P7; P8; P9; P11; P12; P13; P15; P16; P17.
} 


\section{Professores}

"Em todos os momentos. Ciência é sobrevivência" (P2).

"Acredito que a ciência faz parte de tudo em nossa vida, ou seja, no trabalho, no lazer e inclusive enquanto estamos dormindo" (P16).

"Ela está presente em todos os momentos" (P17).

Estes participantes compreendem a ciência de uma modo mais abrangente, não se limitando a visões relacionadas a conteúdos escolares. O estudo da ciência torna-se mais significativo quando os alunos passam a ver sentido no que lhes é ensinado, relacionando as aprendizagens com sua realidade. Instigá-los a observar o mundo de um novo modo, observando os detalhes, permite enxergar os conceitos em vários momentos, em praticamente tudo (IPED, 2017).

A outra categoria que surgiu na análise dos dados foi "quando penso na origem, evolução e explicação das coisas", decorrente das respostas de seis $(19,3 \%)$ alunos $^{8}$ e seis $(33,3 \%)$ professores ${ }^{9}$, um terço deste último grupo.

\section{Alunos}

"Em quase tudo, pois tudo tem a ver com ciências, tudo tem o jeito que foi feito" (A2).

"Quando penso como é formada alguma coisa, ou o porquê das coisas" (A28).

"Quando fico pensando como as plantas conseguem viver só com o ar e os nutrientes" (A30).

\section{Professores}

"Na medicina, na psicologia, na tecnologia" (P4).

"Nas descobertas constantes que ocorrem na medicina, na tecnologia" (P5).

"Quando tento buscar respostas para certas coisas; em saber que tem alguém em estudo para cura de doenças [...]" (P18).

Ambos os grupos entendem a ciência como aquela que tem as respostas para "tudo", dinâmica e esclarecedora. Conforme Borges (2010), está pautada nas descobertas e explicações para os fenômenos, em constante evolução. Para tal, a investigação é o princípio, seguida pelas interações discursivas e a divulgação das ideias, disseminando os conhecimentos (SASSERON, 2016). Áreas como medicina, psicologia e tecnologia, citadas por P4, exemplificam a abrangência da ciência nos mais variados setores.

Já a categoria "quando estou em contato com a natureza" foi decorrente somente das respostas dos alunos, respondida por $12(38,7 \%)$ alunos ${ }^{10}$.

"Em muitas, quando eu planto uma flor ou uma planta, quando cuido de meus animais de estimação, na minha saúde" (A21).

\footnotetext{
${ }^{8}$ A2; $A 7 ; A 9 ; A 10 ; A 28 ; A 30$

9 P4; P5; P6; P10; P14; P18.

${ }^{10} \mathrm{~A} 3$; A16; A17; A18; A19; A20; A21; A24; A25; A26; A29; A31.
} 
"Ao fazer carinho em um animal ou comer uma fruta" (A29).

"Quando estou entre a natureza" (A31).

Para Goldschmidt et al. (2014, p. 158), "persiste uma confusão entre a Ciência e o conceito de natureza ambiental, demonstrando uma visão errônea [...]" da ciência. Estes autores apontam a necessidade de desmistificar esta visão, oportunizando um ensino que aborde as relações entre ciência, inovação e tecnologia, avançando além do conceito ambiental.

"Em momentos específicos" decorreu das respostas de oito (25,8\%) alunos ${ }^{11}$. Nesta categoria, um quarto das respostas faz entender que para estes alunos a ciência é uma forma de conhecimento acessível e estruturada, perceptível em situações específicas.

"Quando eu estou no computador" (A8).

"Na escola" (A14).

"Em casa quando faço os temas" (A15).

Segundo Demo (2011, p. 33), o conhecimento está disponível em diversos meios, tendo sido seu acesso facilitado com a informatização, "característica ineludível dos tempos modernos [...], com nítidas vantagens, seja porque é mais atraente e manejável, seja porque atinge a massa". Diante de tamanhas possibilidades de acesso a respostas, o repasse de conteúdos estanques não é mais suficiente para satisfazer todas as perguntas. A pesquisa é apontada por Demo (2011) como substituta desta transmissão, oportunizando a "reconstrução do conhecimento".

A questão seguinte abordou o conceito de pesquisa. Para os alunos a pergunta questionava o que entendiam por pesquisa. Para os professores, foi perguntado se consideravam-se pesquisadores. As respostas dos alunos geraram três categorias: buscar informações sobre algo que interessa; pesquisar o novo; sem compreensão clara. Já a questão dos professores resultou em quatro categorias: busca frequente por atualização; eventualmente; não tem a pesquisa clara; não se considera pesquisador.

Quase a metade, quinze $(48,4 \%)$ alunos ${ }^{12}$, se enquadrou na categoria "buscar informações sobre algo que interessa", concebendo a pesquisa como meio de esclarecer dúvidas e curiosidades, aprofundando saberes.

"Para esclarecer dúvidas" (A8).

"É um meio de aprender um pouco mais sobre determinado assunto" (A28).

"É quando a gente vai procurar nos livros, internet, uma curiosidade" (A30).

Já outros doze $(38,7 \%)$ alunos ${ }^{13}$ veem a pesquisa semelhante a categoria anterior, entretanto, com um sentido mais voltado a descoberta, do que propriamente um aprofundamento do conhecimento. Constituem a categoria "pesquisar o novo":

"Entendo que com pesquisa você aprende coisas novas, [...]." (A5).

"Pesquisar coisas que você não conhece" (A16).

\footnotetext{
${ }^{11} \mathrm{~A} 1 ; \mathrm{A} 4 ; \mathrm{A} 8 ; \mathrm{A} 12 ; \mathrm{A} 14 ; \mathrm{A} 15 ; \mathrm{A} 22 ; \mathrm{A} 23$.

${ }^{12} \mathrm{~A} 2 ; \mathrm{A} 6 ; \mathrm{A7} ; \mathrm{A} 8 ; \mathrm{A} 11 ; \mathrm{A} 13 ; \mathrm{A} 14 ; \mathrm{A} 19 ; \mathrm{A} 20 ; \mathrm{A} 21 ; \mathrm{A} 22 ; \mathrm{A} 25 ; \mathrm{A} 26 ; \mathrm{A} 28 ; \mathrm{A} 30$.

${ }^{13} \mathrm{~A} 1 ; \mathrm{A} 5 ; \mathrm{A} 9 ; \mathrm{A} 10 ; \mathrm{A} 12 ; \mathrm{A} 15 ; \mathrm{A} 16 ; \mathrm{A} 18 ; \mathrm{A} 24 ; \mathrm{A} 27 ; \mathrm{A} 29 ; \mathrm{A} 31$.
} 
"Eu acho que é ir além do que sabemos" (A18).

"Pesquisar é um processo que objetiva entrar em contato com realidades desconhecidas ou pouco conhecidas, revelando suas características e peculiaridades" (RAUSCH; SCHROEDER, 2010, p. 327). Veiga (2010) complementa ao afirmar que a pesquisa mexe com o espírito investigativo do aluno, aguçando o desejo de explorar novos saberes para sanar a curiosidade. Demo (2011, p. 34) destaca que a pesquisa "[...] tomada como princípio científico e educativo, maneira de saber fazer e de refazer conhecimentos, bem como educar [...] é a energia vital da busca da inovação", emancipando o aluno para não apenas ouvir, mas também dialogar.

Três (9,7\%) alunos (A4; A17; A23) revelaram não demonstrar compreensão do que é pesquisa, dando origem a categoria "sem compreensão clara". Suas respostas foram expressas de modo contraditório. Um (3,2\%) aluno (A3) não se manifestou nesta questão.

"Não entendo nada" (A4).

"Por pesquisa eu entendo tudo" (A23).

Pavão (2017) ressalta que muitas vezes o aluno não tem compreensão do que é a pesquisa por não estar familiarizado com ela. É necessário romper com o ensino transmissivo e aproximar o aluno deste processo, destacando o prazer da descoberta. Desse modo, se estará contribuindo para a formação de cidadãos capazes de atender as necessidades no "novo mundo" em que vivemos, interpretando as muitas informações disponíveis.

Quanto aos professores, questionados se consideravam-se pesquisadores, seis $(33,3 \%)^{14}$, o que representa um terço dos participantes, afirmaram com convicção que são pesquisadores, originando a categoria "busca frequente por atualização":

"Sim, precisamos estar constantemente nos atualizando, pesquisando sobre novas teorias/novos conhecimentos e também sobre aqueles trazidos pelos alunos" (P3).

"Sim, pois estou sempre estudando, pesquisando e me atualizando" (P8).

"Lógico. Todo professor responsável e dedicado é pesquisador" (P11).

Os professores desta categoria demonstram-se preocupados em acompanhar os fatos, estando receptivos a novos conhecimentos e aprendizagens. Possivelmente, pela sua característica investigativa, tendem a instigar seus alunos a também serem pesquisadores. Nas palavras de Demo (2009, p. 16-17), educar pela pesquisa é motivar o "próprio educando, para que surja o novo mestre, jamais o discípulo, [...] é [...] reconhecimento de que o melhor saber é aquele que sabe superar-se".

A categoria "eventualmente" foi respondido por dois $(11,1 \%)$ professores (P2; P4):

"[...]. Tenho uma carga horária de trabalho que me ocupa muito. Pesquiso um pouco ao preparar as aulas que vou propor aos alunos. Leio materiais diversificados e agrego os conhecimentos novos ou reafirmo/refuto os já construídos" (P2).

"Às vezes" (P4).

14 P1; P3; P8; P11; P15; P16. 
Estes professores demonstram que a pesquisa não faz parte de suas rotinas. P4 não mensura frequência, dando a entender que a realiza esporadicamente, em caso de necessidade. P2, por sua vez, informa sua prática com mais detalhes, entretanto, afirma ter uma rotina atarefada, dispondo de pouco tempo para pesquisas aprofundadas.

A categoria seguinte, "não tem a pesquisa clara", decorreu das respostas de cinco $(27,8 \%)$ professores ${ }^{15}$. Retratam uma realidade de profissionais, aqui expressa por mais de um quarto dos participantes, que parecem não conceber, de fato, o que é pesquisar. Ficam em dúvida quando a própria prática pedagógica e seu modo de buscar informações, talvez por associarem o termo "pesquisador" a figura de cientistas, como relatado por Chibeni (2017), e assim não se julgarem.

"Não, me chamaria curiosa, buscadora [...]" (P6).

"Se for considerar o estudo dos problemas atuais, sim" (P7).

"Em parte sim, porque o professor deve estar preparado para explanar um assunto, que dá informação, se torne um conhecimento para o aluno [...]." (P10).

Cinco $(27,8 \%)$ professores ${ }^{16}$, novamente mais de um quarto dos participantes, responderam que não se consideram pesquisadores. Destes, apenas um detalhou sua resposta, os demais responderam apenas "não":

"Não, pesquiso o que preciso para poder transmitir em aula e para o meu conhecimento" (P9).

Este professor é um representante típico do ensino transmissivo, retratado por Demo (2009, p. 13), "fez 'opção' pelo ensino, e passa a vida contando aos alunos o que aprendeu de outrem, imitando e reproduzindo subsidiariamente", apropriando-se de certa quantidade de conhecimento e transmitindo aos alunos.

A questão seguinte indagou os professores sobre o modo com que desenvolvem pesquisa com os alunos. Originaram-se quatro categorias: em livros, Internet, meio social; por meio de debates; temas de interesse do aluno; não desenvolvem pesquisa.

A categoria "em livros, Internet, meio social" refere-se a resposta de cinco (27,8\%) professores ${ }^{17}$. Os distintos meios de pesquisa não formaram categorias separadas pois foram citados conjuntamente pelos professores, de forma generalizada.

"Uso livros e na sala de informática ou mesmo em alguns momentos vivências dos alunos" (P1).

"A pesquisa é feita em laboratórios de informática, em livros, jornais e revistas" (P2).

"Pesquisamos em livros, no laboratório de informática ou em casa (com pais, comunidade escolar). [...]" (P5).

A outra categoria, "por meio de debates", igualmente foi decorrente das respostas de cinco (27,8\%) professores ${ }^{18}$, pouco mais de um quarto dos participantes. Esta categoria preza pelo diálogo e 0

\footnotetext{
15 P5; P6; P7; P10; P14.

16 P9; P12; P13; P17; P18.

17 P1; P2; P4; P5; P11.

18 P7; P8; P14; P15; P16.
} 
intercâmbio de ideias, sendo os resultados decorrentes das pesquisas socializados entre os participantes.

\begin{abstract}
"Inicialmente oriento-os sobre o porquê deste estudo, dou alguns passos a serem seguidos, acompanho e para concluir comentamos o estudo no grande grupo" (P7).

"Proporcionando debates, suscitando temas, inclusive onde necessitam se posicionar. $[\ldots]^{\prime \prime}(\mathrm{P} 15)$.

"Permitindo que eles participem, a partir do tema escolhido, com opiniões, ou seja, sempre permito uma variada forma de soluções das problemáticas levantadas. [...]" (P16).
\end{abstract}

"Temas de interesse do aluno" foi respondido por quatro (22,2\%) professores ${ }^{19}$, aproximando-se também de um quarto, o que mostra uma distribuição equilibrada das respostas. Nesta categoria de pesquisa, bem como na anterior, os professores levam em conta a opinião dos alunos:

"Buscando assuntos que lhes interessam e solicitando/investigando que estudem/pesquisem sobre a fim de realizarem novas descobertas" (P3).

"Fazendo os alunos quererem saber... [...] a pesquisa nada mais é do que a busca pelo que se quer saber. [...]" (P6).

"Através de temas que despertam curiosidade nos alunos" (P12).

Trata-se de um ensino com pesquisa voltado para o interesse dos alunos, o que é muito importante. Segundo Pavão (2017), assuntos descontextualizados e distantes da realidade dos alunos não contribuem para que percebem a presença da ciência e tecnologia no cotidiano, como influenciam e afetam a sociedade.

Dois (11,1\%) professores (P9; P17) relataram que "não desenvolvem pesquisa", sendo a última categoria desta pergunta. Outros dois $(11,1 \%)$ professores (P10; P8) não responderam esta questão.

"Na minha disciplina, quase sempre é nós que pesquisamos e transmitimos esses conhecimentos" (P9).

"Acho que não desenvolvo pesquisa, só faço que relacionem o que aprendem com o seu dia a dia" (P17).

A resposta de P9 nos remete ao que já foi apontado por Demo (2009), quanto ao ensino transmissivo por meio do repasse de conteúdos, geralmente descontextualizado da realidade, mera cópia/reprodução. Enquanto que a resposta de P17 relaciona-se com o exposto por Mbarga e Fleury (2017), procurando ampliar conhecimentos para além da sala de aula.

Aos alunos, por sua vez, foi perguntado se seus professores estimulam a realização de pesquisa em sala de aula e de que forma isto ocorre. As categorias oriundas das respostas foram: pesquisa como exercício em aula; pesquisa na Internet; pesquisa em livros; pesquisa em meio social; não realizam pesquisa.

Chama atenção que, diferente da categoria dos professores, que citaram conjuntamente, livros, Internet e meio social, os alunos citaram estas fontes separadamente, tendo concepções diferentes dos locais e meios para se fazer pesquisa. Vejamos as cinco categorias que emergiram da questão:

19 P3; P6; P12; P13. 
"Pesquisa como exercício em aula", citado por nove (29,1\%) alunos20.

"Sim, em questionários e perguntas" (A10).

"Sim, explicando e passando no quadro ou em folha para lermos" (A19).

"Sim, quando passam atividades relacionadas ao texto" (A31).

"Pesquisa na Internet", citado por sete (22,6\%) alunos ${ }^{21}$.

"Sim, indo na informática para pesquisar coisas sobre o que estamos estudando" (A21).

"Sim, pelos computadores" (A23).

"Sim, pedindo para a gente pesquisar na internet" (A30).

"Pesquisa em livros", citado por cinco (16,1\%) alunos 22

"Sim, muitas vezes no livro didático ou no caderno mesmo" (A5).

"Sim, só em livros" (A11).

"Pesquisando em livros e textos" (A28).

"Pesquisa em meio social", citado por dois (6,4\%) alunos.

"[...] jornais $[\ldots]$ pesquisas com pessoas $[\ldots] "(A 2)$.

"Através de [...] entrevistas [...]" (A7).

"Não realizam pesquisa", citado por dois (6,4\%) alunos (A17; A24). Além destes, outros três $(9,7 \%)$ alunos (A6; $A 12 ; A 14)$ responderam apenas "sim" e três $(9,7 \%)$ não responderam a questão (A3; $A 4$; A9).

Pode-se observar que é através de exercícios em sala de aula que a pesquisa ocorre com maior frequência, seguida por pesquisas na Internet e em livros, em menor proporção. Diferente do informado pelos professores ("por meio de debates"; "temas de interesse do aluno"), os alunos não mencionaram a oralidade como forma de pesquisa, com as quais os professores instigam o diálogo e exploram a curiosidade dos alunos, contextualizando vivências, conforme apontado por Pavão (2017). Entende-se que estas oralidades ocorrem em sala de aula, contudo, os alunos não as percebem de tal forma.

Perguntou-se também aos alunos em quais disciplinas as pesquisas são realizadas. Houve uma variedade de respostas, as quais, por proximidade de vezes, podem ser expressas em pares:

$$
10 \text { - Ciências: } 25 \text { vezes }(22,3 \%)^{23} \text {; História: } 22 \text { vezes }(19,6 \%)^{24} \text {; }
$$

\footnotetext{
${ }^{20} \mathrm{~A} 1 ; \mathrm{A} 10 ; \mathrm{A} 13 ; \mathrm{A} 15 ; \mathrm{A} 18 ; \mathrm{A} 19 ; \mathrm{A} 22 ; \mathrm{A} 25 ; \mathrm{A} 31$.

${ }^{21}$ A8; $A 21 ; A 23 ; A 26 ; A 27 ; A 29 ; A 30$.

${ }^{22} \mathrm{~A} 5 ; \mathrm{A} 11 ; \mathrm{A} 16 ; \mathrm{A} 20 ; \mathrm{A} 28$.

${ }^{23} \mathrm{~A} 1 ; \mathrm{A} 2 ; \mathrm{A} 3$; $\mathrm{A} 4$; $\mathrm{A} 5 ; \mathrm{A} 6 ; \mathrm{A7} ; \mathrm{A} 9 ; \mathrm{A} 10 ; \mathrm{A} 11 ; \mathrm{A} 12 ; \mathrm{A} 13 ; \mathrm{A} 14 ; \mathrm{A} 15 ; \mathrm{A} 16 ; \mathrm{A} 18 ; \mathrm{A} 19 ; \mathrm{A} 20 ; \mathrm{A} 21 ; \mathrm{A} 22 ; \mathrm{A} 23 ; \mathrm{A} 24 ; \mathrm{A} 27 ; \mathrm{A} 28$; A31.

${ }^{24} \mathrm{~A} 1 ; \mathrm{A} 2 ; \mathrm{A} 4 ; \mathrm{A} 5 ; \mathrm{A} 6 ; \mathrm{A7} ; \mathrm{A} 9 ; \mathrm{A} 10 ; \mathrm{A} 14 ; \mathrm{A} 15 ; \mathrm{A} 16 ; \mathrm{A} 18 ; \mathrm{A} 19 ; \mathrm{A} 21 ; \mathrm{A} 22 ; \mathrm{A} 23 ; \mathrm{A} 25 ; \mathrm{A} 27 ; \mathrm{A} 28 ; \mathrm{A} 29 ; \mathrm{A} 30 ; \mathrm{A} 31$.
} 


$$
\begin{aligned}
& 2^{0} \text { - Geografia:17 vezes }(15,2 \%)^{25} ; \text { Artes: } 16 \text { vezes }(14,3 \%)^{26} ; \\
& 3^{0} \text { - Português: } 12 \text { vezes }(10,7 \%)^{27} \text {; Ensino Religioso: } 12 \text { vezes }(10,7 \%)^{28} \text {; } \\
& 4^{0} \text { - Matemática: } 4 \text { vezes }(3,6 \%)^{29} \text {; Educação Física: } 4 \text { vezes }(3,6 \%)^{30} \text {. }
\end{aligned}
$$

Constata-se que as pesquisas ocorrem em maior quantidade nas aulas de Ciências e História e em menor escala em Matemática e Educação Física. Não foi citada nenhuma Língua Estrangeira Moderna, o que é um fato curioso, pois a língua estrangeira faz parte da área de Linguagens, regulamentada pelo MEC, compondo a matriz curricular dos alunos (BRASIL, 2010).

A última questão aplicada com professores e alunos fez menção a crença destes quanto as pesquisas científicas, unindo os conceitos pesquisa e ciência, abordados neste artigo. Perguntou-se: Você vê as pesquisas científicas como atividades passíveis a erros ou que se pode confiar totalmente?

Esta questão procurou verificar a crença dos participantes na ciência, avaliando até onde realmente acreditam na popular frase "está cientificamente comprovado que...", veiculada frequentemente em produtos na mídia, conforme apontado por Chibeni (2017).

Professores e alunos manifestaram a mesma opinião: as pesquisas científicas são passíveis a erros. Assim, ainda que a mídia se utilize do respaldo da ciência para vender seus produtos, relacionandoos a altos graus de confiabilidade, os participantes desta pesquisa posicionaram-se frente ao exposto por Demo (2000, p. 26), ao referir-se que a ciência produz "fragilidades mais controladas", e não certeza absolutas. Vejamos:

Passível a erros: Alunos - 28 vezes $(90,3 \%)^{31}$; Professores - 17 vezes $(94,4 \%)^{32}$.

Se pode confiar totalmente: Alunos - 3 vezes $(9,7 \%)^{33}$; Professores - 1 vez $(5,6 \%)^{34}$

Assim, a ciência sendo uma atividade humana pode equivocar-se. Tendo como princípio a investigação, a qual permite certo valor de prova, é capaz de trazer novas incertezas, conforme citado por Osório (2011, p. 25): "o processo da ciência é contínuo e interminável, sendo que nunca se poderá afirmar que o conhecimento atual permanecerá imutável". Desta forma a ciência é "sensível à desorganização", decorrente do movimento constante do conhecimento.

\section{CONSIDERAÇÕES FINAIS}

Analisando os caminhos percorridos pela ciência, a qual tem considerável origem no senso comum que ao se aperfeiçoar torna-se científica, observou-se, neste estudo, que muitos alunos e professores

\footnotetext{
${ }^{25} \mathrm{~A} 1 ; \mathrm{A} 5 ; \mathrm{A6} ; \mathrm{A7}$; $\mathrm{A} 8 ; \mathrm{A} 9 ; \mathrm{A} 10 ; \mathrm{A} 14 ; \mathrm{A} 15 ; \mathrm{A} 16 ; \mathrm{A} 18 ; \mathrm{A} 19 ; \mathrm{A} 23 ; \mathrm{A} 25 ; \mathrm{A} 27 ; \mathrm{A} 28 ; \mathrm{A} 31$.

${ }^{26} \mathrm{~A} 1 ; \mathrm{A} 4$; $\mathrm{A} 6$; $\mathrm{A} 10 ; \mathrm{A} 14 ; \mathrm{A} 15 ; \mathrm{A} 16 ; \mathrm{A} 18 ; \mathrm{A} 20 ; \mathrm{A} 21 ; \mathrm{A} 23 ; \mathrm{A} 25 ; \mathrm{A} 26$; $\mathrm{A} 27$; $\mathrm{A} 28 ; \mathrm{A} 29$.

${ }^{27} \mathrm{~A} 1 ; \mathrm{A} 2 ; \mathrm{A} 4 ; \mathrm{A} 7 ; \mathrm{A} 14 ; \mathrm{A} 15 ; \mathrm{A} 16 ; \mathrm{A} 18 ; \mathrm{A} 21 ; \mathrm{A} 23 ; \mathrm{A} 24 ; \mathrm{A} 31$.

${ }^{28}$ A2; $A 4 ; A 7 ; A 9 ; A 14 ; A 15 ; A 16 ; A 18 ; A 20 ; A 21 ; A 23 ; A 28$.

${ }^{29} \mathrm{~A} 1 ; \mathrm{A} 14 ; \mathrm{A} 16 ; \mathrm{A} 24$.

${ }^{30} \mathrm{~A} 1 ; \mathrm{A} 9 ; \mathrm{A} 14 ; \mathrm{A} 16$.

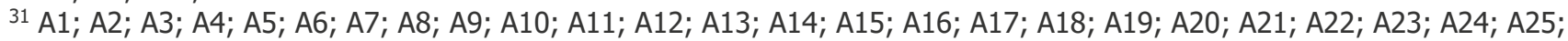
A27; $A 30 ; A 31$.

32 P1; P2; P3; P4; P5; P6; P7; P8; P9; P10; P11; P12; P13; P14; P15; P16; P18.

${ }^{33}$ A26; A28; A29.

34 P17.
} 
não têm compreensão clara do que, de fato, seja ciência, sua abrangência e complexidade. Esta se confunde com a disciplina Ciências, a qual demonstrou ter seu principal foco na natureza ambiental.

No cotidiano a maioria dos professores disse perceber a ciência em todo momento, já os alunos mais a percebem quando estão em contato com a natureza. Apresentam, assim, uma visão reducionista da ciência, sendo que esta contempla diversos outros fenômenos, sobretudo os tecnológicos digitais, tão presentes nas últimas décadas em nosso dia a dia. Outra associação errônea que se faz à ciência é a necessidade de experimentações para ser comprovada, esquecendo-se de outras fontes de dados menos palpáveis que transformam o conhecimento comum em científico.

Quanto ao processo da pesquisa no contexto escolar, os alunos entendem a pesquisa como o aprofundamento de conhecimentos já existentes ou a descoberta de novos conceitos. Entretanto, constatou-se que esta ocorre de modo incipiente. Relatam que a pesquisa se dá predominante por meio de exercícios em aula, como questionários e interpretação de textos, nos quais precisam "pesquisar" para encontrar as respostas. Fazem uso, em menor proporção, de Internet e livros. Já os professores, além de livros e Internet, afirmam explorar o meio social dos alunos, desenvolvendo debates que aproximam o conteúdo de suas realidades, a partir da abordagem oral que realizam com estes.

Apenas um terço dos professores afirmou se considerar efetivamente pesquisador, buscando atualizar-se com frequência. Outras categorias, próximas a um terço, relataram não ter a pesquisa clara ou não se julgarem pesquisadores, possivelmente por associarem a imagem de pesquisadores a cientistas em laboratório, o que Pavão (2017) julga ser um mito que só atrapalha no processo de compreender, ensinar e fazer ciência. Outro mito, citado por Chibeni (2017), se desmistificou nesta pesquisa. Alunos e professores têm a clara compreensão de que a ciência é passível de erros, estando em frequentes (re) descobertas.

O que se percebe, diante do processo da pesquisa como vem sendo desenvolvido nas escolas, é que este se baseia em cópias de conteúdo, com poucos (ou nenhum) elementos que favoreçam o desenvolvimento da autonomia dos alunos. Isto, pois, as práticas de pesquisa baseiam-se predominantemente na resolução de questões a partir de textos selecionados pelos professores, com os quais os alunos têm poucas alternativas de respostas e interpretação, além de trabalharem com conteúdo limitados, muitas vezes sendo um processo apenas reprodutivo.

Em um processo mais profundo da pesquisa, esta compreende o acesso a uma maior quantidade de informações, de modo que os alunos possam ler e selecionar conteúdos, realizar sínteses a partir de suas compreensões, trabalhar com a reescrita (e não apenas com a cópia), desenvolvendo um pensamento reconstrutivo e argumentativo (DEMO, 2009; MENDES, 2013). Outro pesquisador, Ninin (2008), aponta que uma pesquisa bem embasada visa transformar o "aluno-copiador" em um "alunopesquisador", permitindo um trabalho com indagações e opiniões próprias, fundamentadas em autores e com problematização dos conteúdos.

Assim, estas constatações fazem refletir a necessidade de um maior conhecimento do processo da pesquisa, por parte de alunos e professores, visto que da forma como tem se apresentado não vem oportunizando a emancipação dos alunos (DEMO, 2009). Um caminho para mudar esta realidade, na visão destes pesquisadores, se dá por meio da elaboração de projetos de pesquisa, norteados pela metodologia científica. Acredita-se que a pesquisa científica possa desenvolver autonomia e outras 
habilidades na aprendizagem dos alunos, além de oportunizar uma prática pedagógica diferenciada aos professores. Tal assunto será investigado com profundidade na tese de doutorado do primeiro autor deste artigo.

\section{REFERÊNCIAS}

BARDIN, Laurence. Análise de conteúdo. Lisboa: Edições 70, 2006.

BORGES, Ana Paula Aparecida. et al. Visões de Ciência e Cientista utilizando representações artísticas, entrevistas e questionários para sondar as concepções entre alunos da primeira série do Ensino Médio. Anais do XV Encontro Nacional de Ensino de Química, Brasília: Universidade de Brasília, 2010.

BRASIL. Ministério da Educação. Resolução n. 7, de 14 de dezembro de 2010. Fixa Diretrizes Curriculares Nacionais para o Ensino Fundamental de 9 (nove) anos. Disponível em: <http://portal.mec.gov.br/dmdocuments/rceb007_10.pdf> Acesso em: 04 dez. 2015.

CHIBENI, Silvio Seno. 0 que é Ciência? Disponível em: <www.unicamp.br/ chibeni/textosdidaticos/ciencia.pdf > Acesso em: 24 abr. 2017.

DEMO, Pedro. Metodologia do conhecimento científico. São Paulo: Atlas, 2000.

DEMO, Pedro. Educar pela pesquisa. 9. ed. Campinas, SP: Autores Associados, 2011.

DEMO, Pedro. Pesquisa: princípio científico e educativo. 13 ed. São Paulo: Cortez, 2009.

ESTRÁZULAS, Mônica. Prefácio. In: MENDES, Fábio Ribeiro. Iniciação científica para jovens pesquisadores. 2. Ed. Porto Alegre: Autonomia, 2013.

FONTANA, Júlio. A filosofia da ciência de Rubem Alves. Ciberteologia Revista de Teologia \& Cultura. Ano II, n. 7, p. 1-11, set./out. 2006.

GEWEHR, Diógenes. Tecnologias digitais de informação e comunicação (TDICs) na escola e em ambientes não escolares. Lajeado: UNIVATES, 2016. Dissertação (Mestrado em Ensino) Centro Universitário UNIVATES, 2016.

GOLDSCHMIDT, Andrea Inês; et al. Concepções Referentes à Ciência e aos Cientistas entre Alunos de Anos Iniciais e Alunos em Formação Docente. Contexto \& Educação, ano 29, n. 92, p. 132-164, 2014.

IPED. Instituto Politécnico de Ensino a Distância. Importância da ciência para as crianças. Disponível em: <https://www.iped.com.br/materias/reforco-escolar/importancia-cienciacriancas.html> Acesso em: 04 maio 2017.

MBARGA, Gervais; FLEURY, Jean-Marc. O que é Ciência: Curso On-line de Jornalismo Científico. Disponível em: <http://www.wfsj.org/course/pt/L5/L5P00.html> Acesso em: 24 abr. 2017.

MENDES, Fábio Ribeiro. Iniciação científica para jovens pesquisadores. 2. Ed. Porto Alegre: Autonomia, 2013.

NININ, Maria Otília Guimarães. Pesquisa na escola: que espaço é esse? O do conteúdo ou o do pensamento crítico? Educação em Revista, v. 48, p.17-35. 2008. 
OSÓRIO, Marianne Vieira. Análise das concepções de ciência de uma professora de biologia e de alunos de uma escola pública em São Paulo. São Paulo: Universidade Presbiteriana Mackenzie, 2011. Monografia (Licenciatura em Ciências Biológicas) - Universidade Presbiteriana Mackenzie, 2011.

PAVÃO, Antonio Carlos. Ensinar Ciências Fazendo Ciência. Disponível em: <http://hpc.ct.utfpr.edu.br/ charlie/docs/PPGFCET/4_TEXTO_01_ENSINAR\%20CI\%C3\%8ANCIAS \%20FAZENDO\%20CI\%C3\%8ANCIA.pdf> Acesso em: 05 maio 2017.

PERUJO Serrano, Francisco. Pesquisar no labirinto: a tese de doutorado, um desafio possível. São Paulo: Parábola Editorial, 2011.

RAUSCH, Rita Buzzi; SCHROEDER, Sylvia Loch. A inserção da pesquisa nas séries iniciais do ensino fundamental. Atos de Pesquisa em Educação, v. 5, n. 3, p. 315-337, 2010.

SASSERON, Lúcia Helena. Interações discursivas e investigação em sala de aula: o papel do professor. In: CARVALHO, Anna Maria Pessoa de. (Org). Ensino de Ciências por investigação: condições para implementação em sala de aula. São Paulo: Cengage Learning, p. 41-61, 2016.

UOL. Clique Ciência: Quem veio primeiro, o ovo ou a galinha? 10/09/2013. Disponível em: <https://noticias.uol.com.br/ciencia/ultimas-noticias/redacao/2013/09/10/clique-ciencia-quem-veioprimeiro-o-ovo-ou-a-galinha.htm> Acesso em 21 abr. 2017.

VEIGA, Ilma Passos Alencastro. A aventura de formar professores. 2. Ed. Campinas: Papirus, 2010. 